\title{
Food storage and carrion feeding in the fiddler crab Uca lactea
}

\author{
Tae Won Kim* \\ Hopkins Marine Station, Stanford University, 120 Oceanview Blvd, Pacific Grove, California 93950, USA
}

\begin{abstract}
Food hoarding is an adaptive strategy that enhances survival and reproductive success in food-scarce environments. It has been assumed that food hoarders, especially vertebrates, have the ability to cache food based on their current requirements and expected reproductive success. The present study provides empirical evidence that food storage in aquatic invertebrates is dependent on the availability of food and semilunar intertidal rhythms. The white-clawed fiddler crab Uca lactea, which inhabits food-scarce sandy mudflats, usually feeds on organic materials in sediment and occasionally on animal carrion, including conspecifics. This food is brought by the fiddler crabs into their burrows, presumably to be consumed during flood tides or heavy rains when the crabs cannot emerge to feed at the surface. When food was supplemented in the sediment every other day, females tended to store food-enriched sediment into their burrows. This behavior peaked around spring tides, when females were reproductively most active (i.e. mate-searching and mating). These results suggest that females may increase their reproductive effort by storing food.
\end{abstract}

KEY WORDS: Caching • Crustaceans • Deposit-feeder • Fiddler crab • Food availability . Food hoarding

\section{INTRODUCTION}

Food hoarding (or caching), defined as handling of food to conserve it for future use, is an adaptive strategy utilized by a variety of animals (Vander Wall 1990). Hoarding is generally assumed to increase survival probability and reproductive success in foodscarce environments. Temporal variation in the food supply may be one of the critical selective forces leading to the evolution of food-hoarding behavior (Andersson \& Krebs 1978, Vander Wall 1990). Food hoarding has been thoroughly studied in vertebrates such as birds and mammals (e.g. Roth \& Vander Wall 2005, de Kort \& Clayton 2006, Raby et al. 2007). Among invertebrates, only terrestrial arthropods are well known to hoard food for future consumption (Vander Wall 1990). For example, bees hoard food for their young, carabid beetles hoard seed (Alcock 1976), and orb-web spiders wrap prey for future consumption (e.g. Eberhard 1967, Champion de Crespigny et al. 2001).
There are several reports suggesting the possibility of food hoarding in aquatic invertebrates. Among deep-sea animals, sedentary deposit feeders such as echiuran, sipunculan, and polychaete worms may cache food (Jumars et al. 1990, Hughes et al. 1994, Levin et al. 1997, Shields \& Hughes 2009). Food hoarding has also been anecdotally reported in decapod crustaceans (e.g. Salmon 1984, O'Dowd \& Lake 1989, Wolcott \& O'Connor 1992, Kyomo 1999). However, surprisingly very few empirical studies have been conducted on the behavior of food hoarding in relation to food availability for aquatic invertebrates.

Fiddler crabs (genus $U_{C a}$ ) live on intertidal flats composed of sand and/or mud (Crane 1975). These deposit feeders usually consume benthic algae, meiofauna, and other small particulate organic materials deposited by flood tides in the sediment (Hoffman et al. 1984, McLain \& Pratt 2010). However, some Uca species also exhibit carrion feeding, hunting, and cannibalism (Koga et al. 1995). Salmon (1984) was the first to suggest that fiddler crabs may hoard food, reporting 
that female $U$. vocans scraped up surface mud and carried it into their burrows, perhaps because it contained a higher concentration of food.

In the present study, carrion-feeding and foodstorage behavior of Uca lactea is described for the first time. To determine whether sediment storage is foodhoarding behavior, we tested whether crabs stored sediment more frequently when food was supplemented on the sediment. We also examined whether there were differences in storage behavior between sexes. Additionally, because feeding activity has been related to tidal rhythms in fiddler crabs (Kim et al. 2004a), as well as in other animals (e.g. Meyer-Rochow \& Brown 1998), storing frequencies were observed in relation to semilunar cycles and reproductive rhythms.

\section{MATERIALS AND METHODS}

Natural history of the study species. There are approximately 100 species of fiddler crabs in the world, most of which live on intertidal sand or mudflats (Crane 1975). Individual fiddler crabs dig burrows in the sediment as shelter against predation or harsh environmental conditions (Crane 1975). The burrows ( $\sim 30$ to $50 \mathrm{~cm}$ in depth) also function as incubation chambers (Christy \& Schober 1994). The crabs are not active during flood tides or heavy rain when their habitat is covered by water. When tides recede, they come out of their burrows and feed on the surface. Males use a single small cheliped for feeding and the other enlarged claw only for fighting or attracting females. In contrast, females have 2 small chelipeds and use both for feeding, fighting, and defense.

Uca lactea have 2 mating modes. In burrow mating, males build courtship structures (semidomes) at their burrows (Kim et al. 2004b) and then court females by waving their enlarged claws. Receptive females search for possible mates by visiting male burrows for mating. In surface mating, males mate with females on the surface of the female burrow by approaching neighboring females (Kim et al. 2006). Females incubate eggs in the burrows for about $2 \mathrm{wk}$ before releasing larvae in the burrows during spring tides (Yamaguchi 2001). Both sexes can mate with multiple partners. The reproductive rhythm of $U$. lactea follows semilunar tidal cycles during the mating season from June to August (Yamaguchi 2001, Kim et al. 2004a). This timing of the release of larvae may occur when escape from predation is maximized (Christy 2003). The reproductive rhythm varies depending on the environment and geographic location. Although reproductive activity peaks around neap tides in Korea (Kim et al. 2004a), peak reproduction occurs around spring tides in Japan (Yamaguchi 2001).
Carrion feeding. Crabs were observed from June 10 to July 30, 2003 on an intertidal sandy mudflat in Amakusa Island, Kumamoto, Japan ( $32^{\circ} 32^{\prime}$ N, $130^{\circ} 24^{\prime}$ E). Maximum tidal amplitude during the study period was approximately $4 \mathrm{~m}$ (from 0.2 to $4.2 \mathrm{~m}$ in tidal height). A population of Uca lactea inhabits the upper intertidal mudflat, which is usually covered by high tides twice within a $24 \mathrm{~h}$ period. The duration of habitat exposure to air ranges from approximately 4 to $7 \mathrm{~h}$, depending on the tidal periods. Whenever conspecific carrionfeeding behavior was observed on the mudflat, the sex of the crabs was determined and the behavior was recorded with a digital camera (Panasonic Lumix DMC FZ-1) and a camcorder (Panasonic NV-5).

Food supplementation. Four $1.5 \times 1.5 \times 0.3 \mathrm{~m}$ plastic net enclosures were established in the middle of the intertidal flat. A $5 \mathrm{~cm}$ strip of plastic tape was sewn to the upper edge of the mesh to prevent crabs from climbing out of the enclosure. Each enclosure encompassed natural crab densities of approximately 40 males and 40 females. Crabs inside enclosures were captured by plugging the burrow entrance using a stick or a custom-made device described by Kim et al. (2008). Each crab's carapace was marked using paint marker pens, using a combination of 4 colored dots on each of 4 equally divided regions of the carapace. Forty individuals of each sex were marked in each enclosure. Unmarked individuals were removed from the enclosures. When there were fewer than 40 individuals, crabs were added into the enclosures. Marks placed on females did not remain detectable throughout the study, probably because of molting and abrasion, so individual identities were confirmed using a map that denoted the location of each crab's burrow. Because females rarely change their burrows in a given day, this identification method allowed for a calculation of the proportion of food-storing individuals.

As the receding tide exposed the marsh surface, $10 \mathrm{~g}$ of sardine flakes mixed with 31 of water was added to 2 of the enclosures and 31 of water to the other 2 enclosures. The treatment was repeated every other day to allow a between-day comparison within enclosures. After 1 semilunar cycle, the food treatment for each enclosure was reversed and the experimental procedure was repeated for another semilunar cycle. This procedure eventually produced 4 samples for each treatment. Because it rained heavily on the second day after the spring tide in the second semilunar cycle, the food treatment was conducted on the following day. Two researchers observed 2 plots each (one with food and the other with water only) for 90 min after crabs emerged from burrows, recording the location of the crabs in the enclosures on a map and recording the occurrence of sediment-storing behavior. Some crabs stayed inside their burrows throughout the day. Thus, only crabs that 
were active at the surface were recorded. Typically, after a crab stored sediment for about $90 \mathrm{~min}$, it stopped storing and fed at the surface again. The frequency of surface mating and the number of mate-searching females in each enclosure was recorded for $3 \mathrm{~h}( \pm 90 \mathrm{~min}$ from low tide) each day. All mate-searching females could not be followed until mating, because mate-searching females spent a long time visiting several males, and it was not possible to track each female while collecting other data. Thus, the number of mate-searching females was used as an indicator of the frequency of burrow mating (Koga et al. 1998, deRivera et al. 2003).

Statistical analysis. A repeated-measures ANOVA was used to assess whether food addition or the interaction between food addition and days influenced the number of females on the surface and the frequency of sediment storage from the first to the fourth day of food treatment and from the first to the third day of non-treatment in each cycle. The frequency of surface mating and the number of mate-searching females were compared between food treatments for 8 consecutive days of each cycle using a repeated-measures ANOVA design. The assumption of equal between-group correlations and group variances ('sphericity') was not violated in all repeated-measures ANOVA tests (Zar 1999, p. 259). A Mann-Whitney $U$-test was used for between-day (foodtreated days and non-treated days) comparisons of foodtreated plots. For this test, the variables between 2 plots with the same treatment were pooled because there was no significant difference between the two. The MannWhitney $U$-test was also used to compare the proportion of sediment-storing individuals between sexes. To determine whether variation in the frequency of sediment storage was related to tidal rhythms, the day of the spring tide was defined as 0 and the absolute value of the number of days from the spring tide (e.g. $4 \mathrm{~d}$ before spring tide $=4$ ) was used in a regression analysis of the relationship between tidal phase and storage frequency. To determine if food supplementation influences surface mating and female mate-searching, the number of surface mating events and the number of mate-searching females were pooled, respectively, throughout the days because these data were not significantly different between food-supplemented days and non-supplemented days. Analyses were carried out using SPSS 12.0 for Windows and all means are presented $\pm 1 \mathrm{SE}$.

\section{RESULTS}

\section{Carrion feeding and hoarding behavior}

When crabs encountered a dead fish or conspecific on the sediment, they scavenged the carrion. Dead fish were consumed by 2 males and 1 female (Fig. 1A), and
2 crabs were observed ( 1 male and 1 female) attempting to drag dead fish into their burrows. Dead conspecifics were observed to be consumed only by females (Fig. 1B, $;$ n = 16). All of the dead crabs found were males $(n=16)$. At least 8 females $(50 \%)$ were observed dragging dead males into their burrows (Fig. 1C). On the following day, all the females that hoarded dead males removed the males' large chelipeds from their burrows (Fig. 1D). Evidently females were unable to consume the tissue in the large claw so the claw was discarded. Occasionally, individuals of either sex were also found to store sediment into their respective burrows. In these instances, the crabs scraped the surface of the sediment with their 4 walking legs and carried it into their burrows (Fig. 1E,F, see Video S1 in the supplement at www.intres.com/articles/suppl/b010p033_supp/).

\section{Sediment storage in response to food fluctuation}

After food was added, crabs fed on the organic materials contained in the sediment for 1 to $2 \mathrm{~min}$, within their home ranges (15 to $30 \mathrm{~cm}$ from the burrow). They then repeatedly scraped the surface of the sediment and carried it into their burrows. For the days when food was added to enclosures, a significantly greater percentage of females $(26.3 \pm 7.9 \%)$ stored sediment in their burrows compared to males, which rarely cached $(0.8 \pm 0.6 \%)$ (Mann-Whitney $U$-test: $U=11, \mathrm{n}_{1}=\mathrm{n}_{2}=9, \mathrm{p}<0.01$ ) (Fig. 2, Table 1). Food supplementation did not influence the number of females on the surface on food-treated days both when compared to control plots (food effect: $F_{1,6}=0.065, \mathrm{p}=0.808 ;$ food $\times$ day effect: $F_{3,18}=0.691, \mathrm{p}=$ 0.569 ) and non-treated days (food-treated days: $34.2 \pm$ 4.7 females, non-treated days: $33.4 \pm 4.9$ females; $U=$ 29.5, $\mathrm{n}_{1}=9, \mathrm{n}_{2}=7, \mathrm{p}=0.832$ ) (Table 1 ). However, food supplementation significantly increased the number of sediment-storing females on food-treated days in comparison to control plots (food effect: $F_{1,6}=37.435, \mathrm{p}=$ 0.001 ; food $\times$ day effect: $F_{3,18}=5.893, \mathrm{p}=0.006$ ) (Fig. 2) and to non-treated days (food-treated days: $8.2 \pm 2.3 \mathrm{fe}-$ males, non-treated days: $1.0 \pm 0.6$ females; $U=11, \mathrm{n}_{1}=9$, $\mathrm{n}_{2}=7, \mathrm{p}=0.03$; Fig. 2). In non-treated days, neither the number of females on the surface (food effect: $F_{1,6}=$ $0.080, \mathrm{p}=0.787$; food $\times$ day effect: $F_{2,12}=0.073, \mathrm{p}=0.930$ ) nor the number of sediment-storing females (food effect: $F_{1,6}=1.742, \mathrm{p}=0.235 ;$ food $\times$ day effect: $F_{2,12}=0.161, \mathrm{p}=$ 0.853 ) was significantly different between experimental and control plots.

\section{Sediment-storage rhythm}

The frequency of females storing sediment varied with the semilunar tidal rhythms (Fig. 2). Sediment 

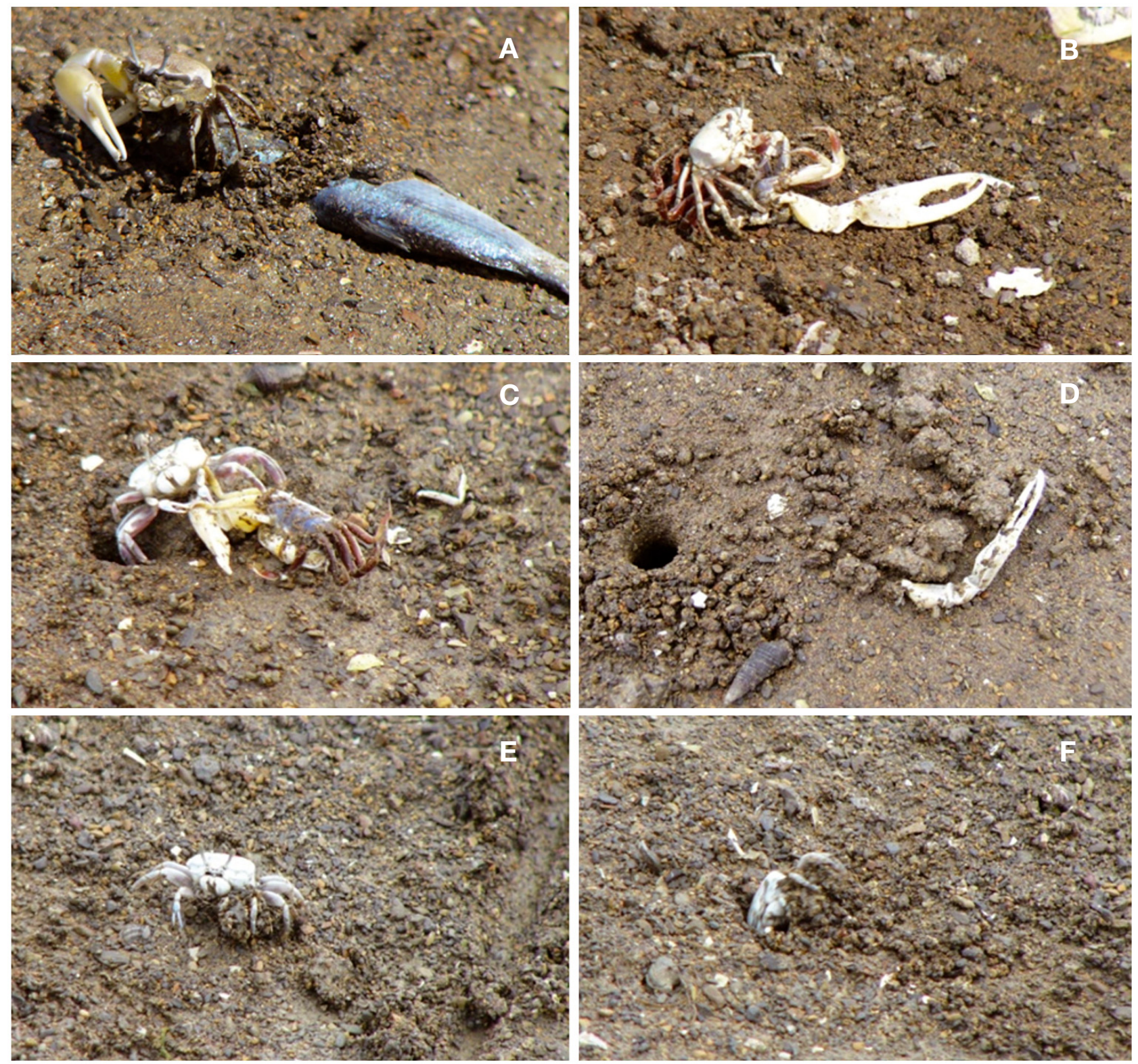

Fig. 1. Uca lactea. (A) Male feeding on a dead fish. (B) Female feeding on a dead male. (C) Female carrying a dead conspecific into her burrow. (D) Major claw of a dead male that was carried out of the female burrow after processing. (E) Female scraping and carrying sediment. (F) Female entering burrow with sediment

storage was most frequent during spring tides. Females did not store sediment during neap tides, even after food was supplemented. There was therefore a significant, negative relationship between the frequency of storage and the number of days before spring tide $\left(\mathrm{r}^{2}=0.768, F_{1,8}=26.409, \mathrm{p}<0.001\right)$.

\section{Sediment storage and mating mode}

The number of sediment-storing females was highly correlated with the number of surface mating events
(Spearman correlation: $Z=1.789, \mathrm{p}=0.0053$ ), but not with the number of mate-searching females $(Z=1.661$, $\mathrm{p}=0.096)$. The mean frequency of surface mating was higher in the experimental plots $(3.3 \pm 0.7$ events $)$ than in the control plots $(1.1 \pm 0.3$ events), although statistical differences were not found (food effect: $F_{1,6}=4.337$, $\mathrm{p}=0.08$; food $\times$ day effect: $\left.F_{7,42}=1.256, \mathrm{p}=0.295\right)$. The number of mate-searching females, an index of burrow mating, did not differ between food treatments (experimental: $1.3 \pm 1.7$ females, control: $0.8 \pm 0.9$ females; food effect: $F_{1,6}=0.701, \mathrm{p}=0.435$; food $\times$ day effect: $\left.F_{7,42}=2.074, \mathrm{p}=0.095\right)$. 


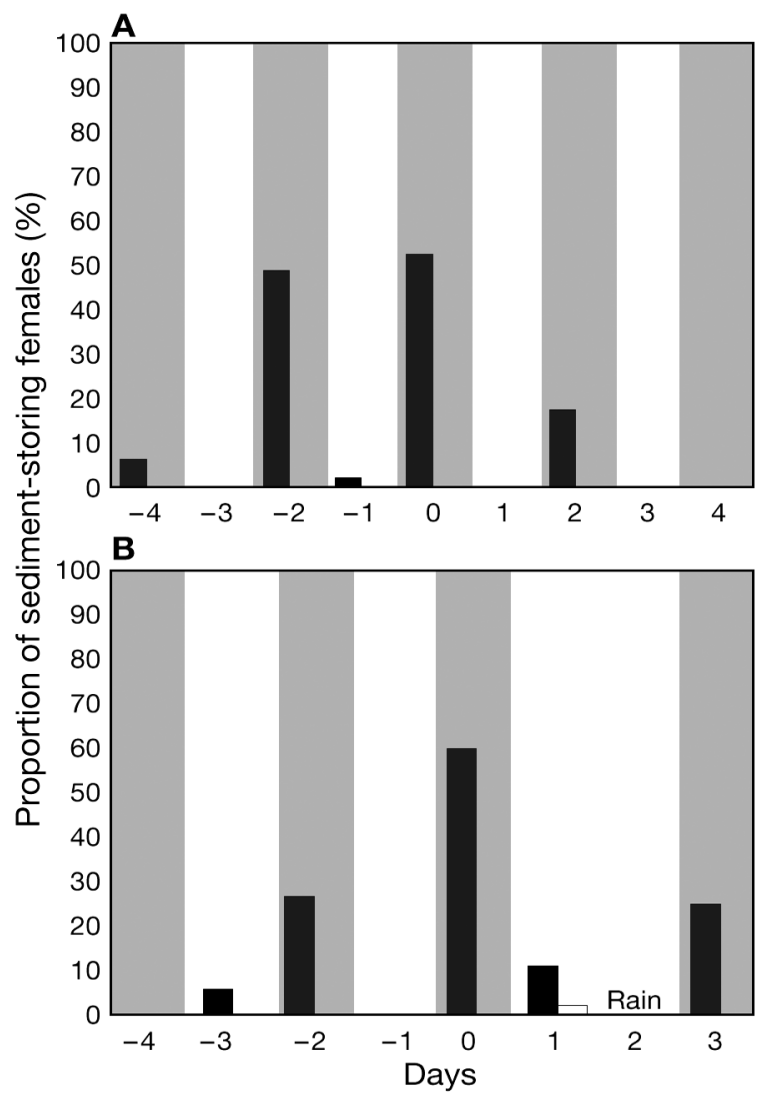

Fig. 2. Uca lactea. Percentage of sediment-storing females in the experimental plots (black bars) and control plots (white bar) on each day in the (A) first and (B) second semilunar cycle. Day 0 is the day of spring tide. Shaded days (grey) represent days when food was supplemented. Only 1 white bar is visible (B), as data for control plots $=0$ on all other days. 'Rain' represents the day when the experiment could not be conducted due to rainfall. Data in plots of the same treatment were pooled, since no significant difference was found between plots

\section{DISCUSSION}

Due to technical difficulties, it was not confirmed in the present study whether the fiddler crab Uca lactea consumed stored food in burrows. However, observa- tions made of the crabs during the present study strongly suggest that food hoarding for future consumption is occurring in this species. First, female crabs were observed storing carrion in their burrows after they ate a portion of it. Second, females increased their sediment storage frequency in response to unexpected increases in food availability. This latter observation is the first experimental evidence in aquatic invertebrates to suggest that the crabs cache food depending on food availability in the sediment. They may consume hoarded material during periods when they cannot feed on the mudflat during flood tides or heavy rain.

For deposit feeders that regularly feed on organic matter deposited in sediments, carrion is a rich but rare energy source, making scavenging of carrion, when possible, an adaptive feeding strategy (Grahame 1983). Carrion feeding or scavenging may be directly connected to food-hoarding behavior. If deposit feeders find a large amount of food but cannot consume it immediately, hoarding it in their burrows or at secure sites could be the best tactic for escaping feeding competition and possible food deprivation. Because carrion is a rare food source for sediment-dwelling crabs, they may hoard carrion into their burrows for later consumption. Sediment storage also frequently occurred when sediment contained unusual amounts of food. Therefore, carrion hoarding and sediment storage are both responses to sudden increases in food availability, and the function of both behaviors may be the same.

It is noteworthy that females were more likely to store food than males, especially around the time of peak reproductive activity. In many other animals, including arthropods, food-hoarding activity is more pronounced in females, likely because females need more energy to produce eggs and offspring (Vander Wall 1990). The greater dependence of females on food-storage behavior in fiddler crabs may be closely related to the different feeding and reproductive strategies of the 2 sexes. In a separate study, males responded to fluctuations in the food supply by in-

Table 1. Comparison of sediment storage between experimental plots and control plots (food-supplemented vs. non-supplemented days, mean $\pm \mathrm{SE}$ ). Data in plots of the same treatment were pooled, since no significant difference was found between plots. n: number of days

\begin{tabular}{|c|c|c|c|c|c|c|c|}
\hline & $\mathrm{n}$ & $\begin{array}{l}\text { No. } \\
\text { ind. on } \\
\text { surface }\end{array}$ & $\begin{array}{c}\text { Male } \\
\text { No. of } \\
\text { sediment- } \\
\text { storing ind. }\end{array}$ & $\begin{array}{l}\text { Percentage } \\
\text { range of } \\
\text { storing ind. }\end{array}$ & $\begin{array}{l}\text { No. } \\
\text { ind. on } \\
\text { surface }\end{array}$ & $\begin{array}{c}\text { Female - } \\
\text { No. of } \\
\text { sediment- } \\
\text { storing ind. }\end{array}$ & $\begin{array}{l}\text { Percentage } \\
\text { range of } \\
\text { storing ind. }\end{array}$ \\
\hline \multicolumn{8}{|c|}{ Supplemented days } \\
\hline Experimental & 9 & $62.3 \pm 2.5$ & $0.5 \pm 0.1$ & $0-5.7$ & $34.2 \pm 4.7$ & $8.2 \pm 2.3$ & $0-60$ \\
\hline Control & 9 & $59.9 \pm 1.5$ & $0.1 \pm 0.1$ & $0-1.7$ & $35.7 \pm 4.6$ & $0 \pm 0$ & 0 \\
\hline \multicolumn{8}{|c|}{ Non-supplemented days } \\
\hline Experimental & 7 & $64.5 \pm 2.9$ & $0 \pm 0$ & 0 & $33.4 \pm 4.8$ & $1.0 \pm 0.50$ & $0-11$ \\
\hline Control & 7 & $58.1 \pm 2.6$ & $0.1 \pm 0.1$ & $0-1.7$ & $38.1 \pm 5.8$ & $0.1 \pm 0.1$ & $0-2.3$ \\
\hline
\end{tabular}


creasing their time spent feeding and did not increase their courtship activity on days when they were provided with an unexpectedly large amount of food (Kim et al. 2008). Male crabs exhibited an increase in courtship activity $1 \mathrm{~d}$ after food supplementation (Kim et al. 2008). In contrast, females did not decrease the frequency of mate searching on the surface, but increased their sediment-storage frequency when supplemented with extra food documented in the present study. Although females may reduce the amount of time feeding on the surface by increasing the investment of caching, the energetic benefit-cost ratio of caching females would be higher than that of noncaching females. This strategy of hoarding food to process it later in the burrows would be advantageous in situations when the supply of food in the sediment is neither constant nor accessible. For males, feeding on the surface yields them adequate energy to court and this obviates the need to cache food. However, females may spend time feeding in burrows to obtain enough energy for reproduction.

There could be an argument that increased courting and feeding activity by males in the food-supplemented plots can increase female sediment-storing behavior. However, sediment storage occurred only during approximately 90 min after receding tides, when most of the crabs are involved in feeding. Also, there were few interactions observed between sexes that indicated sexual harassment and/or competition over food. Therefore, there was little evidence in support of the view that male activity may be a cause of female caching activity.

Furthermore, the number of sediment-storing females was highly correlated with the number of surface mating events, but not with number of mate-searching females. Although not statistically significant, there were more surface-mating females in the foodsupplemented plots. In contrast, the number of matesearching females did not differ between treatments.

As food supplementation or female caching activity may induce males to approach females for surface mating, it is hard to determine which sex has the initiative to choose mating tactics. However, it is probable that supplemented food can affect the relative payoffs of alternative reproductive tactics of females by increasing the reproductive success of surface-mating females. Females ready for breeding search for mates by visiting male burrows and may not change their reproductive tactics even when food conditions change. Perhaps females that mate with males in male burrows and then incubate underground can produce a full clutch without needing to consume additional cached food because their ovaries have been fully developed (Yamaguchi 2001). Also, females that mated in male burrows could not feed for approximately 2 wk while incubating eggs in the burrows. In contrast, females that were not ready for breeding displayed an alternative surface mating strategy, whereby they mated on the surface until they ovulated. These females may supplement their daily food intake by caching. Hence, caching may be a means by which surface-mating females are able to increase their reproductive success by increasing the number of their eggs or improving the quality of eggs through an extra supply of food. In a food-supplementation study on the burrow-mating species Uca terpsichores, females in the food-added enclosures neither showed increased mate-searching activity nor any food-storage behavior (Kim et al. 2010).

Together, these studies suggest that food-hoarding behavior may be more common in situations where food is scarce. The habitat of Uca lactea in Kumamoto, Japan is considerably sandier than the habitat of the same species in Korea. The muddier the tidal flat, the more organic particles the sediment generally contains (McLain \& Pratt 2010). In a previous food-supplementation study with Korean populations, food-storage and carrion-feeding behaviors were rarely observed (Kim $\&$ Choe 2003). This suggests that relatively nutrientpoor environments may be an important factor favoring food-hoarding behavior in some populations of this species. Given that a number of sedimentdwelling aquatic invertebrates generally live in foodscarce environments (Jumars et al. 1990) and have their own burrows for secure places (Gingras et al. 2008), food hoarding and sediment storage might be a widespread adaptation across a diversity of taxa in aquatic environments.

Acknowledgements. Special thanks go to Y. Henmi and Aitsu Marine Station of Kumamoto University for providing facilities and to K. Sakamoto for helping with field work. Thanks to J. C. Choe, J. Christy, J. Faria, A. Greenley, E. Allen Herre, Sanha Kim, S. Lappan, P. Łukasik, R. Rissanen, S. Vander Wall, V. Weaver, and C. Wood for helpful discussions and comments on early versions of the manuscript. I also thank 4 anonymous reviewers for improving the manuscript. The experiment described herein complies with the current laws of Japan.

\section{LITERATURE CITED}

Alcock J (1976) The behavior of the seed-collecting larvae of a carabid beetle (Coleoptera). J Nat Hist 10:367-375

Andersson M, Krebs J (1978) On the evolution of hoarding behavior. Anim Behav 26:707-711

Champion de Crespigny FE, Herberstein ME, Elgar MA (2001) Food caching in orb-web spiders (Araneae: Araneoidea). Naturwissenschaften 88:42-45

Christy JH (2003) Reproductive timing and larval dispersal of intertidal crabs: the predator avoidance hypothesis. Rev Chil Hist Nat 76:177-185

> Christy JH, Schober UM (1994) A test for resource-defense mating in the fiddler crab Uca beebei. Anim Behav 
48:795-802

Crane J (1975) Fiddler crabs of the world. Princeton University Press, Princeton, NJ

de Kort SR, Clayton NS (2006) An evolutionary perspective on caching by corvids. Proc Biol Sci 273:417-423

deRivera CE, Backwell PRY, Christy JH, Vehrencamp SL (2003) Density affects female and male mate searching in the fiddler crab, Uca beebei. Behav Ecol Sociobiol 53: $72-83$

Eberhard W (1967) Attack behavior of diguetid spiders and the origin of prey wrapping in spiders. Psyche (Stuttg) 74:173-181

Gingras MK, Dashtgard SE, MacEachern JA, Pemberton SG (2008) Biology of shallow marine ichnology: a modern perspective. Aquat Biol 2:255-268

Grahame J (1983) Adaptive aspects of feeding mechanisms. In: Vernberg FJ, Vernberg WB (eds) The biology of Crustacea, Vol 8. Environmental adaptations. Academic Press, New York, NY, p 65-107

Hoffman JA, Katz J, Bertness MD (1984) Fiddler crab depositfeeding and meiofaunal abundance in salt marsh habitats. J Exp Mar Biol Ecol 82:161-174

- Hughes DJ, Ansell AD, Atkinson RJA (1994) Resource utilization by a sedentary surface deposit feeder, the echiuran worm Maxmuelleria lankesteri. Mar Ecol Prog Ser 112: 267-275

Jumars PA, Mayer LM, Deming JW, Baross JA, Wheatcroft RA (1990) Deep-sea deposit-feeding strategies suggested by environmental and feeding constraints. Philos Trans $\mathrm{R}$ Soc Lond A 331:85-101

Kim TW, Choe JC (2003) The effect of food availability on the semilunar courtship rhythm in the fiddler crab Uca lactea (Brachyura:Ocypodidae). Behav Ecol Sociobiol 54: 210-217

Kim TW, Kim KW, Srygley RB, Choe JC (2004a) Semilunar courtship rhythm of the fiddler crab Uca lactea in a habitat with great tidal variation. J Ethol 22:63-68

Kim TW, Christy JH, Choe JC (2004b) Semidome building as sexual signaling in the fiddler crab Uca lactea (De Haan) (Brachyura: Ocypodidae). J Crustac Biol 24:673-679

Kim TW, Kim TK, Hong SK, Choe JC (2006) Surface mating as an alternative mating strategy in the fiddler crab Uca lactea. J Ecol Field Biol (Ecol Soc Korea) 29:49-53

Kim TW, Sakamoto K, Henmi Y, Choe JC (2008) To court or not to court: reproductive decisions by male fiddler crabs in response to fluctuating food availability. Behav Ecol Sociobiol 62:1139-1147

Kim TW, Christy JH, Rissanen JR, Ribeiro P, Choe JC (2010)

Editorial responsibility: Victor Meyer-Rochow,

Bremen, Germany
Effect of food addition on the reproductive intensity and timing of both sexes of an intertidal crab. Mar Ecol Prog Ser 401:183-194

Koga T, Goshima S, Murai M, Poovachiranon S (1995) Predation and cannibalism by the male fiddler crab Uca tetragonon. J Ethol 13:181-183

Koga T, Backwell PRY, Jennions MD, Christy JH (1998) Elevated predation risk changes mating behaviour and courtship in a fiddler crab. Proc Biol Sci 265:1385-1390

Kyomo J (1999) Feeding patterns, habits and food storage in Pilumnus vespertilio (Brachyura: Xanthidae). Bull Mar Sci 65:381-389

Levin L, Blair N, DeMaster D, Plaia G, Fornes W, Martin C, Thomas C (1997) Rapid subduction of organic matter by maldanid polychaetes on the North Carolina slope. J Mar Res 55:595-611

McLain DK, Pratt AE (2010) Food availability in beach and marsh habitats and the size of the fiddler crab claw, a sexually selected weapon and signal. Oikos 119:508-513

Meyer-Rochow VB, Brown PJ (1998) Possible natural circaseptan rhythm in the beach beetle Chaerodes trachyscelides White. Acta Neurobiol Exp (Warsz) 58:287-290

O'Dowd DJ, Lake PS (1989) Red crabs in rain forest, Christmas Island: removal and relocation of leaf-fall. J Trop Ecol 5:337-348

Raby CR, Alexis DM, Dickinson A, Clayton NS (2007) Planning for the future by western scrub-jays. Nature 445 : 919-921

Roth JK, Vander Wall SB (2005) Primary and secondary seed dispersal of bush chinquapin (Fagaceae) by scatterhoarding rodents. Ecology 86:2428-2439

Salmon M (1984) The courtship, aggression and mating system of a 'primitive' fiddler crab (Uca vocans: Ocypodidae). Trans Zool Soc Lond 37:1-50

Shields MA, Hughes DJ (2009) Large-scale variation in macrofaunal communities along the eastern Nordic Seas continental margin: a comparison of four stations with contrasting food supply. Prog Oceanogr 82:125-136

Vander Wall SB (1990) Food hoarding in animals. University of Chicago, Chicago, IL

> Wolcott DA, O'Connor NJ (1992) Herbivory in crabs: adaptations and ecological considerations. Integr Comp Biol 32: 370-381

Yamaguchi T (2001) The mating system of the fiddler crab, Uca lactea (Decapoda, Brachyura, Ocypodidae). Crustaceana 74:389-399

Zar JH (1999) Biostatistical analysis, 4th edn. Prentice Hall, Upper Saddle River, NJ

Submitted: March 5, 2010; Accepted: May 19, 2010

Proofs received from author(s): June 17, 2010 